Bernhard Brand, Amine Boudghene Stambouli, Driss Zejli

\title{
The value of dispatchability of CSP plants in the electricity systems of Morocco and Algeria
}

Originally published as:

Bernhard Brand, Amine Boudghene Stambouli, Driss Zejli (2012):

The value of dispatchability of CSP plants in the electricity systems of Morocco and Algeria

In: Energy Policy, 47 (2012) 321-331

DOI: 10.1016/j.enpol.2012.04.073 
Bernhard Brand ${ }^{a}$, Amine Boudghene Stambouli ${ }^{b}$, Driss Zejli ${ }^{\mathrm{c}}$

\section{The value of dispatchability of CSP plants in the electricity systems of Morocco and Algeria}

a Wuppertal Institute for Climate, Environment and Energy, Germany

b University of Sciences and Technology of Oran, Algeria

C Unité des Technologies et Économie des Énergies Renouvelables (TEER), Centre National pour la Recherche Scientifique et Technique (CNRST), Morocco

* Corresponding author: Bernhard Brand, Wuppertal Institute, Döppersberg 19, 42103 Wuppertal, Germany

E-mail: bernhard.brand@wupperinst.org

Phone: +49 202-2492-109

Fax: +49 202-2492-108 


\section{Abstract}

This paper examines the effects of an increased integration of concentrated solar power (CSP) into the conventional electricity systems of Morocco and Algeria. A cost-minimizing linear optimization tool was used to calculate the best CSP plant configuration for Morocco's coaldominated power system as well as for Algeria, where flexible gas-fired power plants prevail. The results demonstrate that in both North African countries, storage-based CSP plants offer significant economic advantages over non-storage, low-dispatchable CSP configurations. However, in a generalized renewable integration scenario, where CSP has to compete with other renewable generation technologies, like wind or photovoltaic (PV) power, it was found that the cost advantages of dispatchability only justify CSP investments when a relatively high renewable penetration is targeted in the electricity mix.

\section{Introduction}

In recent years, concentrated solar thermal power (CSP) technologies have received increased attention not only from the electricity sector, but also from the media and research. One focal point of interest, and a strong contributor to the current popularity of CSP, concerns the desert regions of North Africa. Here, where solar irradiation is high and unused land abundant, many observers see significant opportunities for large-scale deployment of the technology. Promoters of green electricity export scenarios, like Desertec (Dii, 2011) or the Mediterranean Solar Plan (UfM, 2011), give CSP a paramount role in North Africa, particularly with regard to its geographical proximity to Europe as a solar electricity export destination.

Instead of examining such renewable export scenarios, the present work examines the effects of CSP integration into local electricity markets. Many North African governments already have their own policy goals for renewable energy in their future electricity mixes (Brand and Zingerle, 2010). For local planners and decision-makers, it is important to know to what extent CSP technology can be integrated into their countries' electricity systems and how this can be carried out in the most cost-efficient manner. Very often, economic considerations about renewable energy costs are limited to a mere comparison of the levelized costs of electricity (LCOE). If compared on the basis of this metric, the results show that wind - and by now, even photovoltaic (PV) power - features lower electricity generation costs than CSP 
(Kost and Schlegel, 2010). But choosing technologies on the basis of levelized cost comparisons alone can be misleading. Joskow (2010) points to the shortcomings of such an approach, stating that an LCOE-based comparison would generally overvalue intermittent generation technologies compared with dispatchable power plants.

CSP plants become dispatchable when they are outfitted with thermal storage systems, enabling them to store solar energy during daylight hours and transform it into electricity at a later time. On electricity markets, this ability to control the power output brings about two sources of economic value that are not reflected in a mere LCOE-based analysis. ${ }^{1}$ First, there is the "time of delivery value" (Sioshansi and Denholm, 2010), representing the cost savings within the daily dispatch of the power system. In CSP plants, the electricity production can be shifted to periods of high demand (Morocco and Algeria, for instance, feature pronounced demand peaks in the evening hours), thereby reducing the need for expensive peak load plants. The second source of economic value originates from the CSP plants' ability to provide firm capacity to the power system. If properly designed with thermal storage systems, and potentially also with auxiliary fossil fuel-fired heaters, CSP plants can guarantee full capacity at any time of the year. For the steadily expanding North African power generation systems, this means that CSP plants can avert future investments into conventional power plants - and reduce overall system costs.

The assessment of these economic advantages, in the literature often referred to as the "value of CSP dispatchability" or the "value of CSP storage," is becoming an important research topic, as demonstrated by a number of recent studies. Sioshansi and Denholm (2010) calculate the potential operating profits of CSP plants with thermal storage in the electricity wholesale markets of the U.S. states of California, Texas, Arizona, and New Mexico. An analysis by Aga et al. (2011) focuses on the power markets of California and Spain, applying a numerical model to determine the revenue-maximizing storage configuration of CSP. Nagl et al. (2011) examine the value of thermal storage by applying a dynamic dispatch and investment model to the power system of the Iberian Peninsula (Spain and Portugal), while Poullikas et al. (2010) focus on the integration effects of solar thermal power plants in Cyprus. To date, the

Sioshansi and Denholm (2010) mention a third source of economic value, "ancillary services," such as the provision of regulation and spinning reserves. However, an analysis of this value is not included in the present work. 
North African electricity systems have not been addressed by any model-based CSP integration studies.

For the present study, Morocco and Algeria were selected as case studies because of their promising solar potential, but also because of their distinct electricity systems, which provide an interesting comparison: Algeria features a flexible generation system with a large number of combined cycle (CC) and open cycle (OC) power plants, while Morocco relies on less flexible coal-fired steam power plants. This paper examines the interaction of storage-based CSP plants within these different electricity system environments. Additionally, we analyze what implications a higher share of other fluctuating renewable energy technologies like PV or wind power would have for the integration of solar thermal power plants in Morocco and Algeria.

We performed our analysis using an electricity market model which simulates CSP operation on the short-term level (daily dispatch) as well as in the long run, considering the different CSP penetration scenarios in the countries' future electricity systems. The study begins with a brief analysis of the power systems of Morocco and Algeria and the political strategies for renewable and solar electricity in these countries, followed by an overview of CSP technologies. The modeling approach itself and the assumptions for the scenarios analyzed are described in the subsequent sections. In the concluding section, the model results are analyzed and discussed.

\section{The power generation systems of Algeria and Morocco}

\subsection{The power system of Algeria}

Algeria is one of the world's largest gas producers, and it is not surprising that the country uses this primary energy for domestic electricity generation. Currently, natural gas contributes $98 \%$ of the country's electricity production of around $45 \mathrm{TWh}$. The national power plant inventory consists of about $3.8 \mathrm{GW}$ of open cycle (OC) gas turbines, $2.3 \mathrm{GW}$ of combined cycle (CC) natural gas power stations, and $2.7 \mathrm{GW}$ of gas-fired steam power plants (CREG, 2010). Since the Algerian government prioritizes the use of domestic fuels, it can be expected that gas power plants will continue to dominate the conventional part of Algeria's electricity system in the future. Renewable energies, likewise a domestic energy source, represent a further diversification option for Algeria. 
A recent renewable energy development program published by the Algerian Ministry of Energy (MEM, 2011) identifies CSP and PV as the pillars of future renewable electricity generation. By 2030, it is intended that these technologies together supply about $37 \%$ of the national electricity production. An indicator that Algeria actually has taken steps toward a solar-based renewable energy strategy is the construction of the first integrated solar combined cycle (ISCC) plant in Hassi R'Mel (Central Algeria), as well as the governmentsupported set-up of a local PV module manufacturing industry to supply future domestic PV power plants projects (Photon, 2011). Wind energy, in contrast to the immense solar energy potential, has fewer development options and is given only a minor 3\% share in the Algerian power mix by 2030. Likewise, few expansion options exist for hydropower, which today totals $160 \mathrm{MW}$ of installed capacity.

\subsection{The power system of Morocco}

As the only North African country without any noteworthy fossil fuel energy reserves, Morocco must import almost all of its primary energy. Coal power plants, fueled by imported hard coal, form the backbone of the country's generation system. With $1.8 \mathrm{GW}$ of installed capacity (Morocco's total capacity is $6.4 \mathrm{GW}$ ), they contribute about $45 \%$ of the country's forecasted electricity production of 26.5 TWh (ONE, 2010). It can be expected that at least for the next decade, this technology will continue to dominate the Moroccan electricity mix, as additions of approximately $2.0 \mathrm{GW}$ of new coal-fired power stations are envisaged in the near future to meet the country's steadily growing electricity demand (Hajroun, 2010).

About $12 \%$ of Morocco's electricity demand is currently supplied by OC and CC gas power generation, and this share is expected to rise with additional CC power plants coming online in the near future. Liquid fuels (used in diesel- or oil-fired steam plants) still provide $13 \%$ of total demand, but the use of these energy resources will decrease in the long run due to high oil prices. With limited expansion possibilities, the share of hydropower, currently at $13 \%$, is also set to decline in the future. A special feature of Morocco's power supply is the direct import of electric energy from Spain via a submarine interconnector through the Strait of Gibraltar. In 2010, this amounted to a substantial 14\% of Morocco's electricity consumption. Wind energy currently covers only $2 \%$ of national electricity demand, although this share is likely to increase by 2020 if Morocco's electricity utility, Office National d'Electricité (ONE), rolls out a 2.0 GW wind development project, as planned. Solar energy, the country's second renewable energy asset, is also receiving strong government support. The Moroccan 
government recently embarked on a solar roadmap called the Moroccan Solar Plan, which targets the implementation of $2.0 \mathrm{GW}$ of solar power plant projects through the end of this decade. Initially intended solely for solar thermal technologies, part of the $2.0 \mathrm{GW}$ portfolio shall now also include PV technologies, although the exact proportions within the program are not yet known. A recently created government agency, the Moroccan Agency for Solar Energy (MASEN), is in charge of steering the roll-out of the Moroccan Solar Plan (Masen, 2010).

\section{CSP technology}

Concentrated solar thermal power plants can be categorized into four different technology types: parabolic trough systems, linear Fresnel mirrors, central receiver systems, and dish stirling systems. In this study, parabolic trough CSP plants have been chosen as the technology of reference. ${ }^{2}$ Through their success in commercial operations in a multitude of projects worldwide, they now represent today's most widespread CSP technology. At least for the coming decade, these plants are expected to dominate the CSP market (Sargent \& Lundy, 2009). Standard parabolic trough plants are made of the following basic components: (1) a parabolic mirror collector field that produces solar energy by heating a synthetic heat transfer fluid (HTF); (2) the power block, consisting of a heat exchanger, a steam generator, and a steam turbine; and (3) a two-tank molten-salt thermal storage system. The configuration of these engineering components is represented by the following main economic sizing parameters of parabolic trough plants in our model analysis:

- Nominal capacity

- Solar multiple (SM)

- Storage size

The nominal power block capacity is measured in MW, while the solar multiple, a dimensionless parameter, expresses the relative size between the collector field and the power block. An SM of 1.0, for instance, equates to a mirror field that is able to drive the power block at nominal capacity under design-point conditions. These conditions are usually defined as the direct normal irradiation (DNI) on a typical solstice day at noon (Montes et al., 2009). Higher solar multiples allow the plant to produce surplus thermal energy, which can be stored 
for later use. The plant's storage capacity is rated by the number of hours (h) during which a fully charged storage system can supply thermal energy to feed the turbine at nominal power. Different combinations of SM and storage size change the properties of the plant's dispatchability, enabling the plant to be tailored to the flexibility requirements of the surrounding electricity system (Brand and Missaoui, 2011).

\section{Model description}

A bottom-up power supply model was used to analyze the integration of CSP into the electricity markets of Algeria and Morocco. The model is based on a linear optimization approach described by Bartels (2009), Swider et al. (2005), and Nagl et al. (2011), where both the cost-minimizing dispatch and the optimal investment pathway are calculated for each country's power generation system. For simplicity, the power systems of Morocco and Algeria are considered to constitute autonomous model regions that do not exchange electricity between themselves or with third neighbors. From this viewpoint, the model can be seen as a vertically integrated state-owned power company that acts as a cost-minimizing agent on its national electricity system, operates all existing power plants, and makes decisions about investments into new capacity. We opted for this model approach because it appears to fit very well with the current situation in Morocco and Algeria, where the state still rules over the power markets as a single agent. In the model, investments are carried out over 5-year periods, beginning with the year 2010. Each period consists of 32 representative days, with two typical load days (a working day and a weekend day) for each of the four seasons, and four typical meteorological situations per season. The limitation to 32 typical days, instead of the 365 days of a full year, was necessary to keep the calculation time within reasonable limits. Provided that the technical characteristics and operational constraints are respected, the agent has full control over the dispatch of the power generation system in 1hour time steps within each of the representative days. By optimizing dispatch and investment decisions, the total discounted system costs, expressed by the following objective function, are minimized: ${ }^{3}$

$$
T O T A L=\sum_{y} d i s c_{y} \cdot\left(I N V_{y}+O M_{y}+V A R_{y}+F U E L_{y}\right)
$$

\footnotetext{
3 All parameters in upper case represent variables being subject to optimization, whereas the parameters
} in lower case are fixed and set exogenously. 
The four main cost constituents are investment costs, $I N V_{y}$, fixed operation and maintenance costs, $O M_{y}$, variable operation costs, $V A R_{y}$, and fuel costs, $F U E L_{y}$. All cost components are aggregated to 5 -year periods $(y=2010,2015,2020, \ldots)$. The discount factor, disc $y$, brings the costs to a net present value of total costs (TOTAL) in the basis year $2010\left(€^{2010}\right)$. The overall real discount rate is $5 \%$.

A set of equations links the cost components with technical variables. The investment costs, for instance, depend on additions of new plants to the total installed capacity, $C A P_{\text {tech, }}$, (in MW) of the specific technology class (tech = coal, gas, csp, wind, ...). Variable and fuel costs, are a function of the model variable $G E N_{\text {tech,y,d,h }}$, representing the actual electricity generation (in MWh) at any hour $(h=1, \ldots, 24)$ and typical day $(d=1, \ldots, 32)$ of the period $y$.

The optimization is carried out under the boundary condition that total electricity generation meets the demand at any hour of each representative day (energy balance constraint). Demand is exogenously determined by the typical electricity load pattern of Morocco or Algeria $\left(\operatorname{load}_{y, d, h}\right)$ plus an endogenous load referring to electricity drawn by pumps of hydro storage systems. The pumping option plays a role in Morocco, where two hydroelectric pumping systems with an overall capacity of $437 \mathrm{MW}$ are installed.

An additional constraint (peak capacity constraint) prescribes that the available part of the total installed capacity must always be equal to or greater than an exogenous parameter peakload $_{y}$, the load maximum over the period $y$ (usually incorporating a security margin). In Morocco and Algeria, annual peak load projections are part of the electricity demand forecasts published by the national utilities or regulatory bodies. The peak capacity constraint includes a factor for the capacity credit, indicating for each generation technology its capability to provide firm capacity to the power system. For renewable generation technologies, the capacity credit can be understood as the fraction of intermittent capacity by which conventional power generation capacity can be reduced without affecting the loss of load probability of the system (Giebel, 2005). In this sense, the capacity credit of conventional power plants is always $100 \%$, while its value for intermittent renewable technologies is generally lower.

The model likewise incorporates a number of further technical constraints corresponding to the dispatch properties of the thermal generation technologies (ramp-up and shut-down 
behavior, efficiencies, part-load conditions, ...), which cannot be elaborated here in detail (see Bartels (2009) and Swider et al. (2005)).

The contribution of hydropower is generally small in arid countries. Only Morocco holds noteworthy hydro power stations, but the technology in this country has reached its expansion limits, such that no major capacity additions are expected in the future. Nevertheless, operation of the existing capacities still has to be considered in the simulations. The model distinguishes between conventional hydroelectric dams and pumped storage facilities.

For renewable power plants without inherent storage technology (photovoltaic plants and wind farms), operational bounds prescribe that electricity production must always follow the daily variations of irradiation and wind speed. The limiting parameters, $p v$ profile and wind_profile, are set exogenously, ranging from 0 to 1 . They represent a deterministic 24hour output pattern of a typical photovoltaic plant or wind farm and are derived from irradiation and wind speed time series. The model allows a "curtailment" of photovoltaic and wind power, which means that solar or wind resources can be left unused if this is beneficial for overall system costs.

CSP plants require a relatively extensive set of equations to describe their operation and dispatch constraints, which shall be outlined in the following in more detail. The equations differ from the proposal of Nagl et al. (2011) in that the operational constraints more precisely mirror the technical operation of the three main technical constituents of the plant: the mirror field, the power block and storage (see Figure 1). Dumping of solar energy, for instance, is part of the optimization process. Moreover, the equations allow for easy variation of the solar multiple and the storage capacity, which is needed for the later optimization of the CSP configuration (see Section 6.1).

For parabolic trough power plants with a salt storage system, the central task of the linear optimization program is to decide which part of the hourly available solar energy input (CSP_SUPPLY) is directly used to generate electricity and which part is routed to the thermal storage for a later dispatch. The variable CSP_SUPPLY can be regarded as equivalent to the solar thermal energy produced by the mirror field of a CSP plant:

$$
\text { CSP_SUPPLY } Y_{c s p, y, d, h}=C A P_{-} O P_{c s p, y, d} \cdot c_{-} p_{-} p r o f i l e_{d, h} \cdot c s p_{-} \text {multiple }{ }_{\text {tech }}
$$


In this equation, CAP_OP $P_{c s p, y, d}$ is the nominal online capacity of the CSP plant's power block. The exogenous factor csp_profile varies with the hourly changes of direct solar irradiation; csp_multiple represents the solar multiple (SM) of the plant.

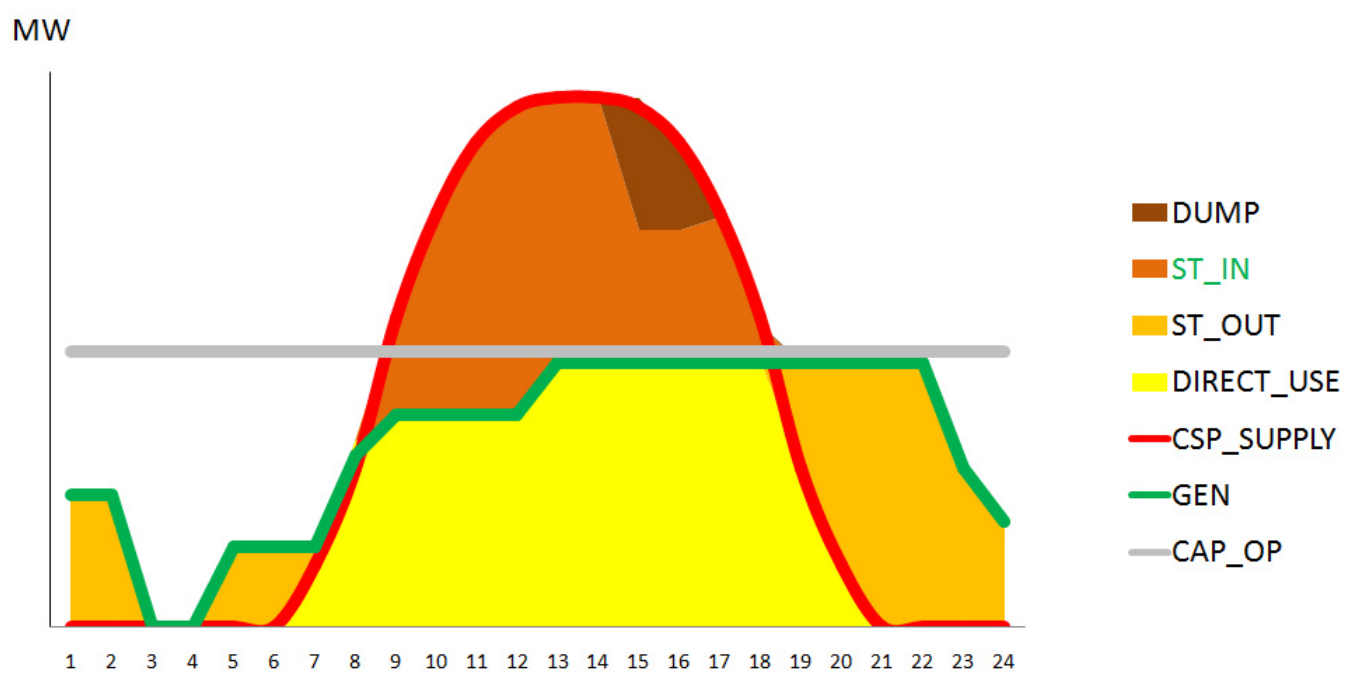

Figure 1. Example operation profile of an SM 2/6h storage CSP plant on a cloudless summer day

Our approach considers a "rolling" 1-day cycle strategy for operation of the parabolic trough plants, as proposed by Sioshansi and Denholm (2010) and Giuliano et al. (2010). The model is simplified by assuming the plant operator has complete foresight and can store energy in anticipation of the next day's demand (consecutive days are, as a further simplification, considered identical). Figure 1 illustrates the interplay between SM, storage size, and the other model variables. The energy generated by the turbine $(G E N)$ is the sum of the energy drawn from the storage system (STORAGE_OUT) and the directly used part of the thermal output of the mirror field (DIRECT_USE):

$$
G E N_{c s p, y, d, h}=S T_{-} O U T_{c s p, y, d, h}+D I R E C T_{-} U S E_{c s p, y, d, h}
$$

The electricity production must always remain lower than the turbine's online capacity:

$$
G E N_{c s p, y, d, h} \leq C A P_{-} O P_{c s p, y, d, h}
$$


The part of the mirror field's output that is used for direct electricity production must not exceed the energy supplied by the solar field (CSP_SUPPLY), and additionally, it must remain below the online capacity:

$$
D I R E C T_{-} U S E_{c s p, y, d, h} \leq C S P \_S U P P L Y_{c s p, y, d, h}
$$

$$
D I R E C T_{-} U S E_{c s p, y, d, h} \leq C A P_{-} O P_{c s p, y, d, h}
$$

All solar energy supplied by the mirror field (CSP_SUPPLY) must be used directly by the power block, sent to the storage tank, or dumped:

$$
\text { CSP_SUPPLY } Y_{c s p, y, d, h}=D I R E C T_{-} U S E_{c s p, y, d, h}+S T_{-} I N_{c s p, y, d, h}+D U M P_{c s p, y, d, h}
$$

Dumping occurs when the storage volume is saturated and there is still more irradiation available than the plant's turbine can directly process. Technically, in this case, the solar collectors would be defocused. Power generated from the storage system cannot be higher than the online turbine capacity:

$$
S T_{-} O U T_{c s p, y, d, h} \leq C A P_{-} O P_{c s p, y, d, h}
$$

Within a one-day storage cycle (24 hours), the amount of energy taken from the storage system must equal the stored energy reduced by a loss factor $\operatorname{loss}_{c s p}$.

$$
\sum_{h} S T_{-} O U T_{c s p, y, d, h}=\operatorname{loss}_{c s p} \cdot \sum_{h} S T_{-} I N_{c s p, y, d, h}
$$


The factor $\operatorname{loss}_{\text {csp }}$ represents thermal and heat exchanger losses during cycling of the storage system. For standard HTF/molten-salt systems, this factor is set at 0.985 (Sioshansi and Denholm, 2010). An additional constraint takes account of the limited capacity of the thermal energy storage. Rated in hours (storage_hours) of nominal plant capacity, it represents the upper limit of the energy discharged from the storage system each day:

$$
\sum_{h} S T_{-} O U T_{c s p, y, d, h} \leq \text { storage_hours }_{c s p} \cdot a v_{c s p, d} \cdot C A P_{c s p, y}
$$

Further operational constraints, which are not listed here in detail, exclude events of simultaneous charge and discharge of the storage system, and ensure that the storage system can only be discharged at times when the solar supply is insufficient to run the turbine at nominal capacity.

With the market costs of renewable energies still comparatively higher than conventional power, the model would omit renewable capacity additions in its optimization process, preferring a conventional investment pathway as the least-cost solution. Fixed renewable penetration targets were introduced to bring renewable power into play. The model receives an exogenous constraint in the form of a minimum energy production amount (in $\mathrm{MWh}$ ), which must be supplied by renewable sources. This minimum renewable production is expressed as a percentage share of the total electricity demand and forces the model to actively install as much renewable capacity as is necessary to produce a certain "renewable" percentage (res_share) of the overall power demand.

\section{Assumptions and input parameters}

\subsection{Demand}

The model requires the following demand input parameters: the total annual electricity demand (demand $)_{y}$ ) in TWh for each model period, the projected load maximum $\left(\right.$ peakload $\left._{y}\right)$ in $\mathrm{MW}$, and the typical hourly load pattern for each representative day $\left(\operatorname{load}_{y, d, h}\right)$. For the demand and peak load data, we utilized demand forecasts published by 
the Moroccan Ministry of Energy (Hajroun, 2010) and the Algerian electricity regulation authority (CREG, 2010).

Table 1. Demand and peak load developments according to Hajroun (2010) and CREG (2010).

\begin{tabular}{|c|c|c|c|c|c|}
\hline & 2010 & 2015 & 2020 & 2025 & 2030 \\
\hline Morocco total demand (TWh) & 26.5 & 40.0 & 57.0 & 85.0 & 116.0 \\
\hline Morocco peak load (MW) & 4600 & 7400 & 9300 & 13900 & 18500 \\
\hline Algeria total demand (TWh) & 45.2 & 60.0 & 79.0 & $105.0^{*}$ & $140.0^{*}$ \\
\hline Algeria peak load (MW) & 8000 & 11000 & 14500 & $19000^{*}$ & $24700^{*}$ \\
\hline
\end{tabular}

Daily load profiles were retrieved from historical load data available in online databases of the Moroccan electricity utility ONE, and the Algerian transmission system operator Opérateur du Système Electrique (OSE). The load profiles were normalized and linearly scaled up with the respective expected annual demand in future periods. ${ }^{4}$

\subsection{Generation}

Eight generation technologies can contribute to electricity generation in the model: hard coal steam plants (Morocco only), gas-powered steam plants, $\mathrm{CC}$ gas plants, OC gas turbines, liquid fuel power plants (oil and diesel), hydropower (including pumped storage for Morocco), wind, photovoltaics, and CSP.

\subsubsection{Conventional power plants}

The model incorporates data from a power plant inventory of Morocco and Algeria (AUPTDE, 2007); the data were updated with publicly available information about recently installed plants and future power plant projects. Technical plant parameters (e.g. plant efficiency, minimum load conditions, and availability) were derived from a recent study of the Tunisian generation system (GIZ, 2011), which we considered a reasonable estimate for Algerian and Moroccan conditions. The same publication provided financial parameters, such

$4 \quad$ Forecasts of future load profile transformations in Morocco and Algeria were not available. It should be noted that model results might change, if, for instance, the midday peak becomes more pronounced in the countries due to progressing industrialization and an increased use of air-conditioning. 
as investment costs, operation and maintenance (O\&M) costs, and variable operation costs, as well as price developments for coal and natural gas. Carbon emission costs are not applied for fossil power plants in North Africa.

\subsubsection{Concentrated solar power plants}

The electricity generation of parabolic trough power plants in the model follows the descriptions outlined in Section 4. One important input parameter is csp_profile tech,d,h $_{\text {, }}$ representing the normalized hourly energy supply of the plant's collector field for each of the 32 representative days. For simplicity, and to distinguish the effects of CSP integration from other, irradiation-dependent effects, we used one irradiation data set for both countries. The input refers to a site in eastern Morocco, not far from the Algerian border (Ouarzazate, average DNI of $2500 \mathrm{kWh} / \mathrm{m}^{2}$ ), for which an online database (Helioclim, 2010) provided hourly DNI irradiation data. These were subsequently processed by the System Advisor Model software (NREL, 2010) to obtain the hourly collector field output values for csp_profile tech,d,h. As for the arid climate of North Africa, it is assumed that all CSP plants are dry-cooled. Likewise, it is assumed that all CSP plants are equipped with auxiliary fossil fuel-fired HTF heaters. The heaters' contribution to net electricity generation is negligible, but their presence guarantees plant capacity at peak load, even without sunshine and when the thermal storage is empty. Electricity system operators often require plants to hold such backup heaters available (Goebel, 2010), as doing so increases the firm capacity of the power system. As a result, a relatively high capacity credit of $90 \%$ is assumed in our model for all parabolic trough configurations.

The financial parameters of parabolic trough power plants mainly depend on the sizing of the three main subunits (mirror field, power block, and storage system). Therefore, the specific investment costs $(€ / \mathrm{kW})$ are a function of the plant's solar multiple and storage capacity. With the help of the component-specific costs database of NREL's System Advisor Model (NREL, 2010), we performed a breakdown of the plant's total specific capital costs for each examined combination of SM and storage capacity, arriving at three cost portions: costs of the collector field $\left(C_{C}\right)$, costs of the power block $\left(C_{P}\right)$, and costs of the storage system $\left(C_{S}\right)$. These costs are considered current equipment costs in the basis year 2010. To obtain costs for the subsequent 
model periods, $y(2015,2020, \ldots)$, we applied a standard learning curve approach (e.g. as described in Junginger et al., 2010):

$$
C_{y}=C_{2010} \cdot\left(\frac{I_{y}}{I_{0}}\right)^{\frac{\lg (P R)}{\lg 2}}
$$

This calculation was carried out for each cost constituent, $C_{C}, C_{P}$, and $C_{S}$, assuming progress ratios (PR) of $P R_{C}=90 \%, P R_{P}=94 \%$, and $P R_{S}=88 \%$ for the collectors, the power block, and the storage systems, respectively (Junginger et al., 2010). The increase in the worldwide cumulative installed CSP capacity from $2010\left(I_{0}\right)$ to future years $\left(I_{y}\right)$ is based on the assumptions of an "optimistic-realistic" global CSP market development scenario, as outlined by Viebahn et al. (2010). The described method can be used to calculate the specific investment costs for the future periods of any plant configuration with different solar multiples and storage capacities. Table 2 displays the cost parameters of one exemplary configuration of an SM2/6h parabolic trough plant until 2030. Fixed O\&M costs are set at $53.8 €^{2010} / \mathrm{kWa}$ and variable costs at $2.3 €^{2010} / \mathrm{MWh}$ (NREL, 2010).

Table 2. Specific investment costs for a parabolic trough plant with SM2 and 6h storage

\begin{tabular}{clccc}
\hline & & \multicolumn{2}{c}{ Specific investment costs $\left(\boldsymbol{\epsilon}^{\mathbf{2 0 1 0}} / \mathbf{k W}\right)$} \\
\cline { 3 - 4 } & & $\mathbf{2 0 1 0}$ & $\mathbf{2 0 2 0}$ & $\mathbf{2 0 3 0}$ \\
\hline \multirow{3}{*}{ SM 2 / 6h } & Collector field & 2800 & 1870 & 1470 \\
& Power block & 1850 & 1460 & 1270 \\
& Storage system & 1430 & 880 & 660 \\
& Total & $\mathbf{6 0 9 0}$ & $\mathbf{4 2 0 0}$ & $\mathbf{3 4 0 0}$ \\
\hline
\end{tabular}

\subsubsection{Wind and PV}

The hourly time series of photovoltaic generation ( $p v \_$profile) is based on an exemplary PV plant with crystalline cell technology at Ouarzazate, while wind profile is derived from wind speed time data from representative wind sites (Tetouan and Essaouira in Morocco and Adrar in Algeria). The specific investment costs for wind and PV plants are shown in Table 3 (EWEA, 2009; IEA, 2009; IEA, 2010; and EPIA, 2010). O\&M costs are estimated at 20.0 $€^{2010} / \mathrm{kW}$ a for PV and $40.0 €^{2010} / \mathrm{kW}$ a for wind power. 
Table 3. Specific investment costs for onshore wind and PV power plants.

\begin{tabular}{lccc}
\hline & \multicolumn{3}{c}{ Specific investment costs $\left(\boldsymbol{\epsilon}^{\mathbf{2 0 1 0}} / \mathbf{M W}\right)$} \\
\hline \multirow{3}{*}{ PV power plants } & $\mathbf{2 0 1 0}$ & $\mathbf{2 0 2 0}$ & $\mathbf{2 0 3 0}$ \\
\cline { 2 - 4 } Wind farms & 2500 & 1380 & 1000 \\
\hline
\end{tabular}

With both technologies providing intermittent feed-in, our estimates for the capacity credits remain conservative, at $5 \%$ for wind power and $0 \%$ for photovoltaic plants.

\section{CSP integration into the conventional power systems of Morocco and Algeria}

In this section, we examine whether the characteristics of Algeria's and Morocco's conventional electricity systems have an effect on the integration efficiency of parabolic trough plants. To facilitate understanding of the basic effects of CSP integration, we assume that until 2025 Morocco will continue to base its conventional generation system on a combination of coal and gas plants, and Algeria will maintain its strategy of prioritizing gas power generation. Furthermore, it is assumed that, apart from hydropower and the already existing wind parks in Morocco, no renewable technology other than CSP will take part in future electricity generation. This restriction was required to discern the influence of the conventional power system on CSP integration from the effects of other intermittent renewable sources. (An analysis of the integration of CSP plants in a renewable power mix with wind and PV is provided in Section 7).

\subsection{Impact of CSP configurations on total system costs}

The first analysis to be performed by the model was to determine the optimal CSP configuration for different solar penetration scenarios in Morocco and Algeria. Two scenarios were examined: (1) a "low penetration" scenario, where the CSP share in both countries increases in a stepwise manner from $0 \%$ in 2010 to 5\% in 2025; and (2) a "high penetration" scenario, where the CSP share climbs to $20 \%$ by 2025 . Several model runs were performed to calculate the total costs $\left(T O T A L_{S M x / y}\right)$ for different combinations of solar multiples and storage capacities. Solar multiple values were set at $x=1,1.5,2,2.5$, and 3, while the corresponding 
storage sizes ranged from $y=0 \mathrm{~h}$ (no storage) to $10 \mathrm{~h}$ in 1 -hour increments ${ }^{5}$. It was found that for each penetration scenario, there is one ideal combination of SM and storage capacity that reduces the total costs to an absolute minimum $\left(T O T A L_{m i n}\right)$. These optimum combinations are shown in Table 4.

Table 4. Cost-minimizing combinations of solar multiple (SM) and storage capacity for the integration of parabolic trough plants into the conventional power systems of Morocco and Algeria until 2025.

\begin{tabular}{lll}
\hline & Morocco & Algeria \\
\hline $\mathbf{5 \%}$ CSP penetration target & SM 1.75 / 4h & SM 1.75 / 3h \\
$\mathbf{2 0 \%}$ CSP penetration target & SM 2/6h & SM 2.25 / 8h \\
\hline
\end{tabular}

Figure 2 depicts contour charts of the surplus costs that incur when SM/storage combinations other than the optimized configurations shown in Table 4 are simulated. The $\mathrm{x}$-axis of each graph refers to the solar multiple and the y-axis to the capacity of the storage system in hours. The surplus costs, or more precisely, the relative deviations from the total cost minimum TOTAL $L_{\text {min }}$

$$
\frac{\text { TOT A }_{S M x / y}}{\text { TOTAL }}-1
$$

are displayed in the colored areas. It can be seen that in the case of the $5 \%$ CSP penetration scenario (Figure $2 \mathrm{a}$ and $2 \mathrm{c}$ ), the cost deviation from the minimum configuration remains relatively low over large areas of SM/storage combinations (see blue area, where the cost deviation is smaller than $0.5 \%$ ). However, if a goal of $20 \%$ CSP penetration is targeted (Figure $2 \mathrm{~b}$ and $2 \mathrm{~d}$ ), this area begins to narrow. Particularly in the case of Morocco (Figure 2b), shifting away from the optimum configuration means a relatively strong penalization by increased total system costs. In the case of Algeria (Figure 2d), this effect appears to be less pronounced. Here, the area of moderate additional costs is larger compared to that of Morocco and extends to CSP configurations with smaller solar multiple and storage sizes. Thus, it can be stated that the dispatchability of CSP plants matters more in the Moroccan power system than in the Algerian one, and that this effect becomes more significant with increasing CSP penetration. 

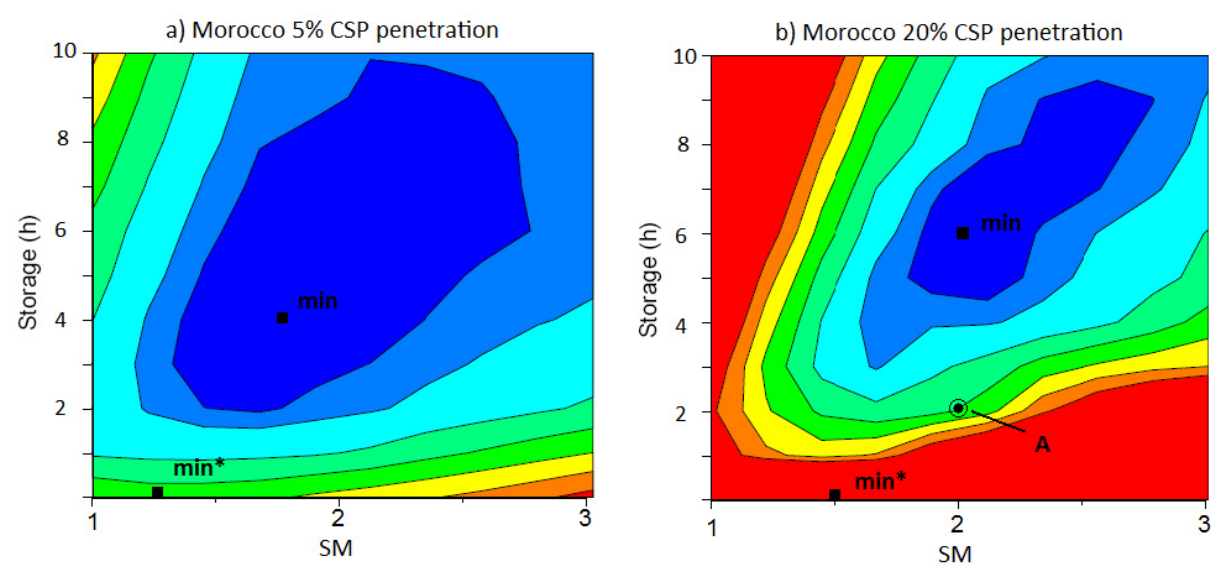

Total cost

deviation

from

minimum (\%)
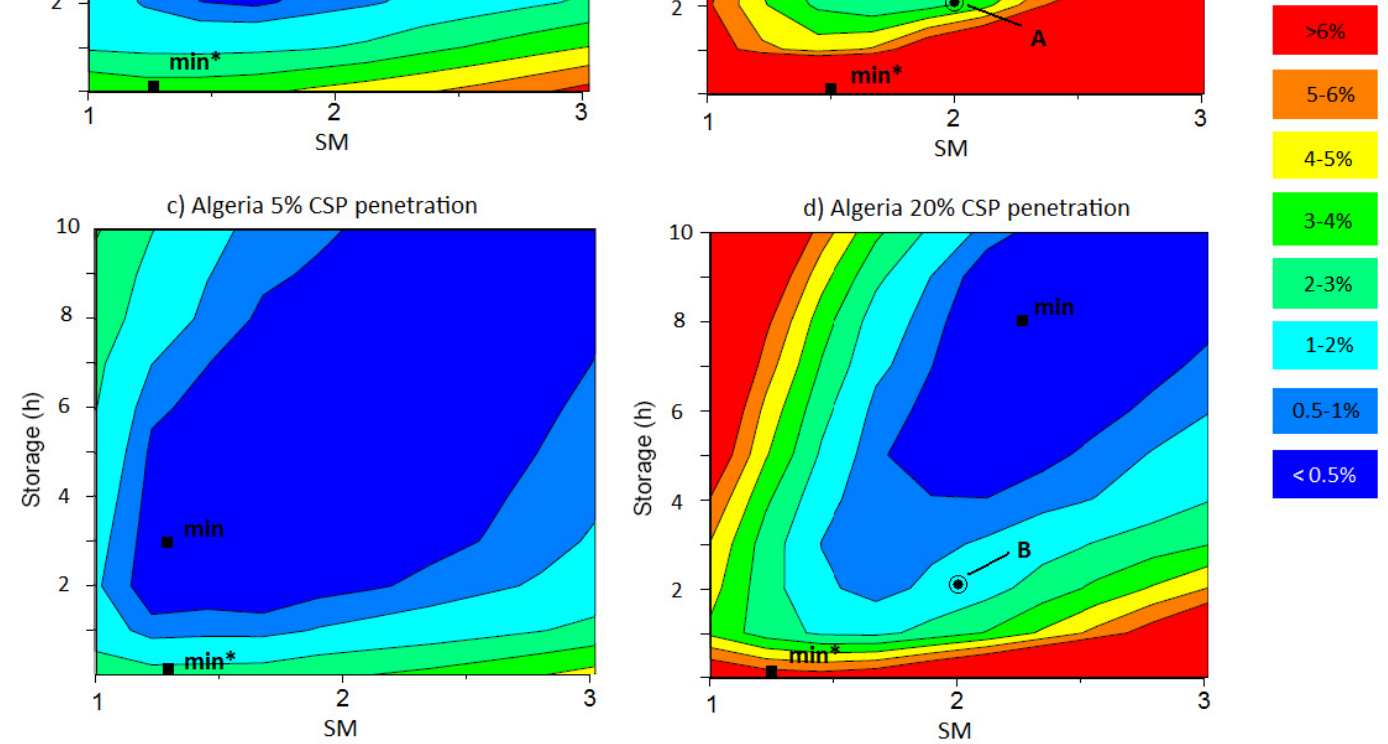

Figure 2. CSP integration costs charts. Deviation from the cost minimum, min, in percent for 5\% and $20 \%$ solar penetration in Morocco and Algeria. The configuration at $\mathrm{min}^{*}$ represents the cost minimum for nondispatchable CSP plants

An explanation of this behavior is qualitatively given by some typical parabolic trough plant operation patterns. Figure 3 (left, bottom) depicts the hourly dispatch of the best-choice CSP configuration (SM2 and 6h storage, min in Figure 2b) in Morocco on a summer day in 2025 in the $20 \%$ CSP penetration scenario. The model optimizes daily electricity production by releasing stored solar energy at hours of high demand, between $19 \mathrm{~h}$ and $23 \mathrm{~h}$, and to a minor extent, also in the morning hours. A look at the details of the plant's operation (Figure 3, left, top) reveals that most of the available solar energy is actually utilized and converted into electricity; only a small amount has to be dumped. Nevertheless, dumping is part of the optimal model solution because there is a trade-off between the avoided investments into a larger thermal storage system and the value of the unused solar energy. 

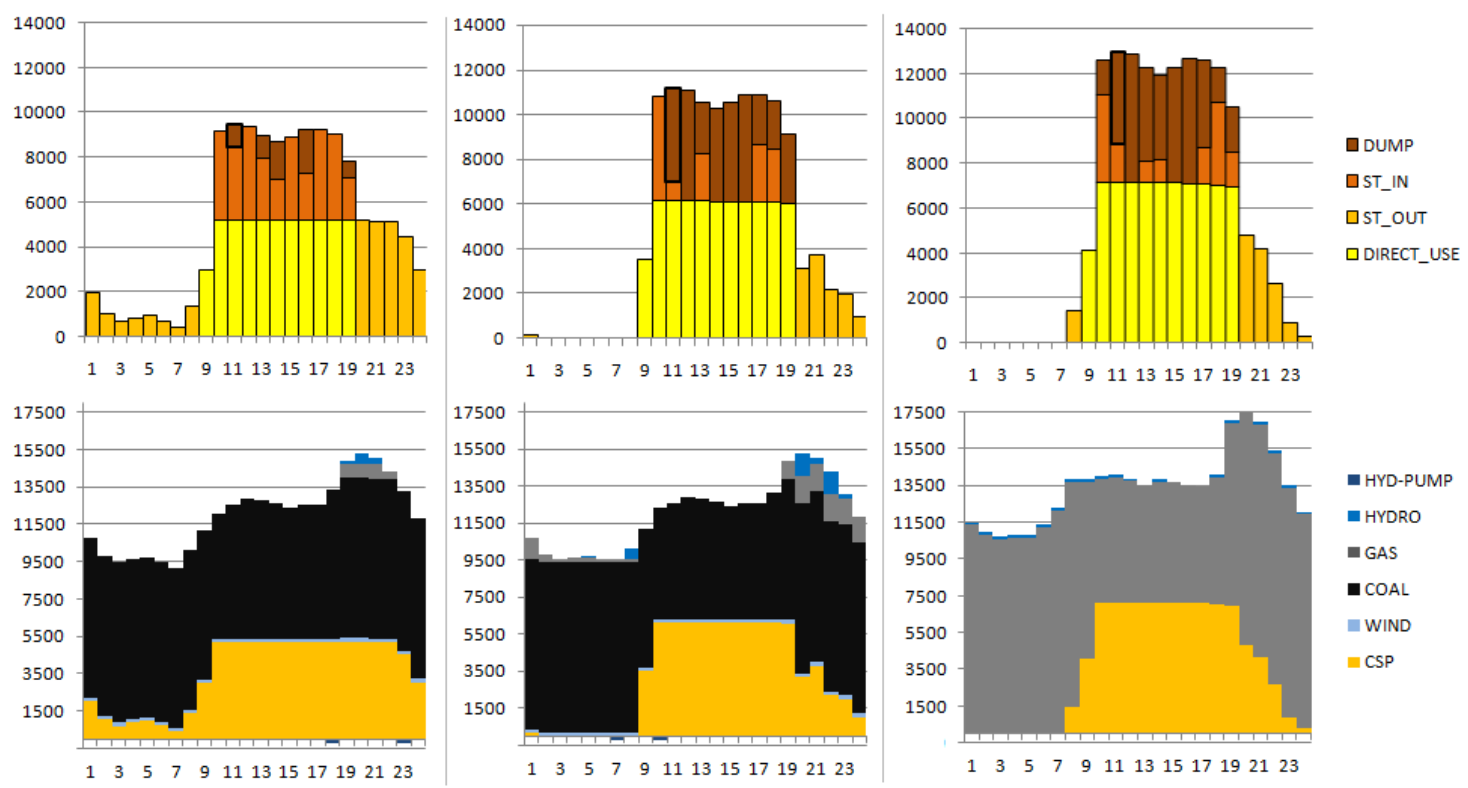

Figure 3. Left: Dispatch (in MW) for 20\% CSP penetration in Morocco, SM2, 6h storage. Center: $20 \%$ penetration, SM2, $2 \mathrm{~h}$ storage (see A in Figure 2a). Right: 20\% CSP penetration in Algeria, SM2, 2h storage (see $B$ in Figure 2d).

Dumping becomes detrimental when the thermal storage capacity is significantly undersized in relation to the collector field. Figure 3 (center) shows the dispatch of an SM2 configuration with only 2 hours of storage capacity. The integration of such inappropriately sized CSP plants leads to an economically suboptimal solution for the entire power system (see point A in Figure 2b). The first and obvious reason for this outcome is that significant amounts of solar energy are wasted because the storage system is undersized. The model is constrained to compensate these losses by installing more CSP plant capacity to achieve the $20 \%$ solar share in the overall electricity mix; the related investments ultimately increase the total costs. The second consequence of an undersized storage system is that the plant's ability to shift solar generation to other periods of the day is reduced: the power system becomes less flexible, and in periods of high demand, hydro and gas power has to be deployed. Another drawback of the limited ability to shift generation is the strong CSP feed-in during the daylight hours from $9 \mathrm{~h}$ to $19 \mathrm{~h}$. This is particularly disadvantageous in the Moroccan case (Figure 3, center, bottom), as coal power plants have to be ramped down or operated in an efficiency-reduced partial load mode. Algeria, alternatively, has fewer problems with large amounts of solar power pushing into generation (Figure 3, right) because flexible gas power plants can more easily (and, comparatively, more cost-efficiently) follow the variations of solar electricity production. As a result, the cost disadvantages are smaller than in the Moroccan case (see point B in Figure $2 d)$. 


\subsection{Monetary value of CSP dispatchability}

The previous section has demonstrated how outfitting CSP plants with storage systems (and, thus, making them dispatchable) has a perceptible impact on the total costs of the entire power system. It has also been demonstrated that the degree of this impact depends on the intended CSP penetration as well as on the characteristics of the electricity system where the plants are to be integrated. In this section, we want to provide a more quantitative picture of the monetary advantages of integrating storage-equipped CSP plants into the electricity systems of Morocco and Algeria. A possible metric for the "value of dispatchability" can be the cost difference between a power system with storage-optimized CSP plants and a system where non-dispatchable CSP plants are integrated. The least-cost configuration of these zero-storage CSP plants is given at a solar multiple of SM1.5 or SM1.25 (depending on country and penetration, see $\min ^{*}$ in Figure 2). Therefore, TOTAL $L_{\min *}$ are the total system costs with SM1.5/0h or SM1.25 plants, while TOTAL $L_{\min }$ refers to the total costs with the optimized $\mathrm{SM} /$ storage combinations found in the previous chapter (see min in Figure 2). Following the general approach of calculating levelized generation costs, we put the cost difference into relation with the amount of CSP electricity produced,

$$
\left(\operatorname{TOTAL} L_{\min *}-\operatorname{TOTAL}_{\min }\right) /\left(\sum_{y} d i s c_{y} \cdot \sum_{c s p, d, h} G E N_{c s p, y, d, h}\right)
$$

and obtained a per-unit value (in $€^{2010} / \mathrm{MWh}$ ), which can be regarded as a proxy for the value of dispatchability. Table 5 lists the results for Algeria and Morocco. To provide a more complete picture, we analyzed not only the penetration cases of $5 \%$ and $20 \%$, but also those of $10 \%$ and $30 \%$.

Table 5. Value of dispatchability. Achievable cost savings per MWh (right) by integrating CSP plants with optimized configurations (left) compared to non-dispatchable configurations under different solar penetration quota.

\begin{tabular}{llllcc}
\hline & \multicolumn{2}{l}{ Optimum configuration } & & \multicolumn{2}{c}{ Value of dispatchability $\left(\boldsymbol{(}^{\mathbf{2 0 1 0}} / \mathbf{M W h}\right)$} \\
\cline { 1 - 2 } \cline { 5 - 6 } $\begin{array}{l}\text { CSP penetration } \\
\text { by 2025 }\end{array}$ & Morocco & Algeria & & Morocco & Algeria \\
\hline $\mathbf{5 \%}$ & SM 1.75 / 4h & SM 1.75 / 3h & & 39 & 29 \\
$\mathbf{1 0} \%$ & SM 2 / 6h & SM 1.75 / 6h & & 38 & 30 \\
$\mathbf{2 0} \%$ & SM 2 / 6h & SM 2.25 / 8h & & 44 & 28 \\
$\mathbf{3 0 \%}$ & SM 2.5 / 9h & SM 3 / 13h & & 55 & 35 \\
\hline
\end{tabular}


An initial finding is that in Morocco the value of dispatchability is, in all penetration cases, significantly higher than in Algeria. This can be seen as an indicator that CSP storage does indeed have a higher economic value in the Moroccan power system than in the Algerian one. We also observe that in Algeria the value of dispatchability remains relatively insensitive to CSP penetration, while, in contrast, the value increases in Morocco, especially at the very high CSP penetration of 30\%. This confirms our previous conjecture that flexible, storagebased CSP plants provide a comparatively better match for Morocco, with its inflexible coalbased power plant environment, than for Algeria, whose large number of gas power stations already offer a flexible power system environment.

\section{CSP integration in a renewable power mix with wind and PV power plants}

While the analysis of the previous section shed a light on the origins and dimensions of the economic advantages of CSP in conventional power systems, it did not discuss the interplay of CSP with other renewable power plant technologies. In Morocco and Algeria, wind and PV are likewise promising renewable diversification options; but unlike CSP, both can only deliver intermittent power, have no storage capacity, and are largely incapable of backing the power system with firm capacity. Nevertheless, both wind and PV power challenge parabolic trough plants with their potentially lower levelized costs of electricity generation (Kost and Schlegel, 2010). Therefore, from the viewpoint of a decision-maker, it would be important to know whether (and if yes, under which conditions) the economic advantages of dispatchability can outweigh the disadvantages of CSP's higher LCOE. To answer these questions, we enabled the model to simulate competition among the three renewable technologies: wind, PV, and CSP. To provide a realistic picture, we decided to orient the analysis toward the "official" renewable energy goals made public by Morocco's and Algeria's governments and planning authorities.

It must be premised that simulations with dispatch and investment models over a long time horizon are generally subject to high sensitivities with regards to the input parameter assumptions. Alterations of cost parameters, for example, the CSP, PV, and wind investment costs, can entail significant changes in the results. Furthermore, it is possible that technology innovations in the CSP sector will lead to a future market preference for other, perhaps less 
costly, CSP technologies (e.g. central receiver systems) instead of the parabolic trough power plants that this study focused on. Because the scope and the space for this article did not permit a sensitivity analysis of such different CSP technology pathways or cost development scenarios, the following findings reflect only the general trends related to one specific cost and technology scenario.

\section{1. $\quad$ Optimized renewable power mix in Algeria}

Algeria has abundant potential for solar power plants, but offers only few promising sites for wind farms. The orientation of the Algerian Ministry of Energy and Mines reflects this reality. In its renewable development program, Programme des Energies Renouvelables et de l'Efficacité Energétique (MEM, 2011), published in 2011, wind is given only a 3\% share of total electricity consumption by 2030, while the goal for photovoltaic and CSP together is set at $37 \%$. We parameterized the model such that wind generation in the overall mix is exogenously constrained to a quota of $3 \%$, while the renewable scenario constraint (res_share $y$, see Section 4) forces PV and CSP generation together to reach $37 \%$ by 2030. The outcome of the simulation thus provides an optimized breakdown between these two solar technologies. This should, from a planner's perspective, allow conclusions about which combination of Algeria's two renewable "pillar" technologies (PV and CSP) is the most costefficient solution in terms of system integration.
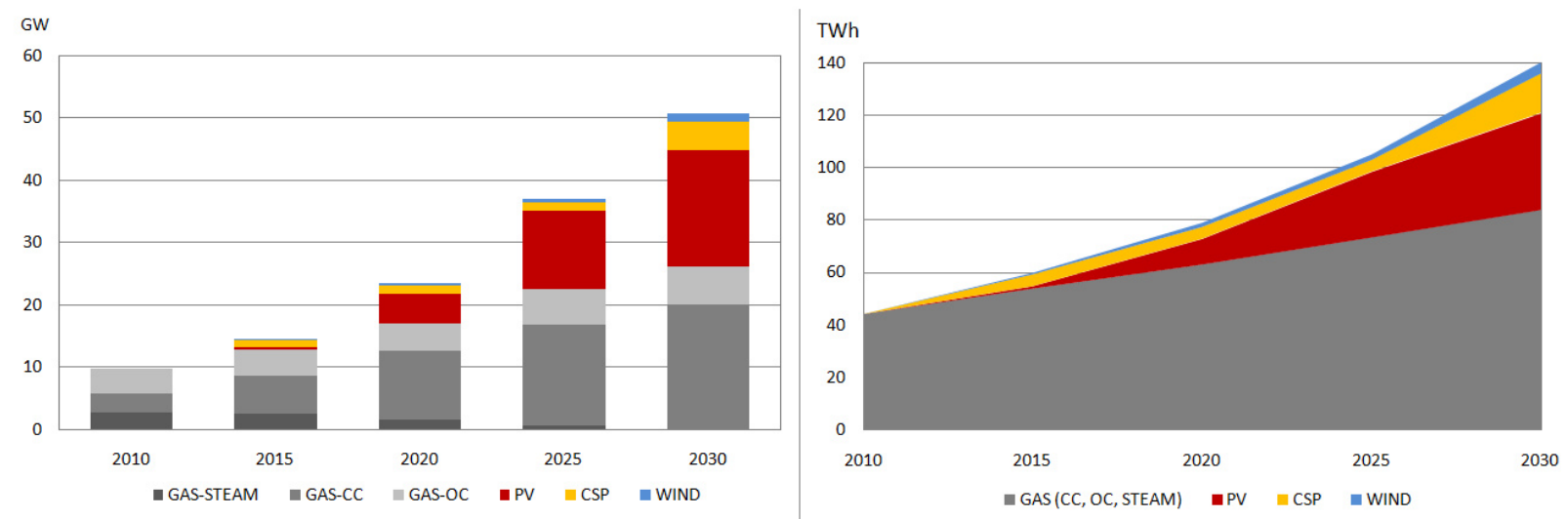

Figure 4. Installed capacities (left) and generation (right) of the Algerian electricity system until 2030.

Figure 4 depicts the results for the Algerian electricity mix until 2030. An initial observation is that both CSP and PV power plants take part in solar generation, although PV to a much greater extent. The dominance of PV can be explained by its lower electricity generation 
costs, which significantly undercut the costs of CSP. This triggers PV capacity additions, while CSP stagnates, at least until 2025. Nevertheless, in 2030 this picture begins to change with a noticeable recovery of CSP. We explain this finding with the previously outlined concept of the value of dispatchability: from a certain PV penetration level on, further photovoltaic feed-in becomes disadvantageous because PV electricity production peaks at the height of the day and cannot be shifted to later hours. More PV capacity leads to a suboptimal system configuration during daily operation, because it either forces PV production curtailment or requires the conventional power plants to reduce their output. Only by introducing renewable technologies with a high value of dispatchability - in other words, CSP plants - can the related cost disadvantages for the overall system be avoided. In our example, simulations lead to an optimal CSP configuration of SM2/6h storage, with an installed capacity of $4.6 \mathrm{GW}$ in 2030 , contributing to $11 \%$ of the 2030 generation mix. The installed PV capacity in 2030 reaches $18.7 \mathrm{GW}$, with a production share of $26 \%$.

\subsection{Optimized renewable power mix development for Morocco}

Unlike Algeria, Morocco doesn't express its renewable goals in electricity production shares, but instead in installed capacity. For wind power, a capacity target of $2.0 \mathrm{GW}$ is foreseen by 2020 (ONE, 2008), which translates into an annual production of around 7.3 TWh, or approximately $13 \%$ of the projected national electricity demand. As the proportions of CSP and PV plants in Morocco are not known, the 2.0 GW solar capacity goal of the Moroccan Solar Plan (Masen, 2010) does not allow any conclusions to be drawn about future solar electricity production. We therefore decided to base our analysis on an estimated production goal of 5.6 TWh by 2020, representing a 10\% share in the national mix. Assuming that this $10 \%$ solar share will be maintained until 2030 , we examined, as in the previously described Algerian case, which combination of PV and CSP capacities would prove the most costefficient for the Moroccan generation system. 

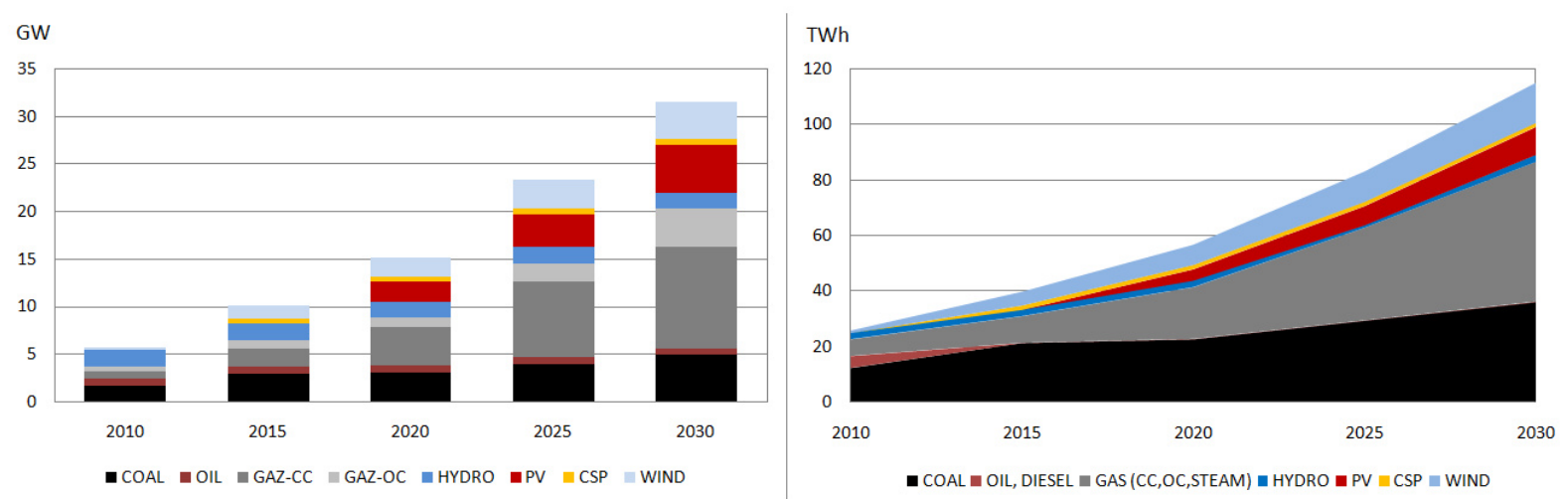

Figure 5. Capacities (left) and generation (right) of the Moroccan electricity system until 2030.

The optimization results in Figure 5 show that for Morocco, a PV-biased solar mix is also preferred until 2030; CSP power plants would only cover a small part of the generation. We carried out several model runs with different combinations of solar multiple and storage capacity and found that the least-cost configuration for CSP is given at SM1.5/3h storage. Its entire production in 2030 , however, would only cover $1.4 \%$ of the total demand (with a capacity of $570 \mathrm{MW}$ ), while the PV share reaches $8.6 \%$ (with around $5 \mathrm{GW}$ capacity). The low requirement for CSP indicates that its value of dispatchabilty remains low when only a small renewable quota ( $10 \%$ solar and $13 \%$ wind) is targeted. Even the $4 \mathrm{GW}$ intermittent wind capacity can apparently still be handled by the conventional electricity system without the need for additional CSP plants. From a purely economic viewpoint, it can be stated that Morocco, with its current solar development plan, should - at least in the short run - rather emphasize projects with "low-hanging renewable fruits" like wind and PV instead of investing into the currently more costly CSP technologies. On the other hand, CSP could very well constitute an appropriate technology if Morocco revised its renewable goals and opted, for example, for more wind power in the future. For instance, the current $2 \mathrm{GW}$ wind target appears relatively small compared to the country's overall wind potential of $25 \mathrm{GW}$ (Benkhadra, 2011). Under high wind penetration, dispatchable CSP plants with high storage capacity will very likely prove a better-fitting renewable complement to the intermittent wind feed-in.

\section{Conclusion}

The ability to store and dispatch electricity distinguishes CSP power from other, intermittent renewable generation technologies and promises general cost advantages when it comes to 
integration into electricity systems. In this study, we used a linear power market optimization model to examine these advantages - the "value of dispatchability" - and quantified the consequences for CSP in different power system environments. Morocco and Algeria, both countries with high ambitions for renewable energy, were chosen as case studies. It was shown that a value of CSP dispatchability exists in both electricity systems, and that this value is influenced by three main factors: (1) the properties of the surrounding conventional power system (e.g. coal- or gas-based power systems), (2) the technical configuration of the CSP plants themselves, and (3) the targeted renewable energy penetration. We observed, however, that the value of dispatchability does not necessarily guarantee the competitiveness of CSP in comparison with other renewable generation technologies. When the targeted amount of renewable generation in an electricity system is low, the value of dispatchability is often not sufficient to justify the investments into CSP capacities. In Morocco, which in our examined scenario targets only a small solar quota, photovoltaic power appears to be the more cost-efficient means of solar electricity generation. Algeria, on the other hand, has subscribed to a solar electricity goal of almost $40 \%$, which can only be reached by a major participation of CSP plants. Nevertheless, drawing final conclusions about the general competitiveness of CSP is still premature, since renewable cost developments and learning rates, especially for CSP, are currently not very well explored. Further uncertainties might likewise emerge from the hardly predictable PV market, which is currently seeing dramatic price drops on a worldwide level. In the not unlikely event that PV power plant costs decrease more quickly than in our assumptions, CSP deployment in Morocco and Algeria would be pushed even further into the future. Another aspect is the future development of alternative storage devices, such as electrochemical storage systems; innovations and lower costs in this area could further challenge the competitiveness of CSP plants in electricity systems. On the other hand, it should also be mentioned that our model did not consider the aspect of grid infrastructure expansion, where CSP might provide certain cost advantages compared to other intermittent renewable technologies. Moreover, there is a political dimension: CSP is considered to have a high potential for creating economic value and jobs in North Africa (Fraunhofer and Ernst \& Young, 2011), and certain governments might become inclined to prioritize this technology in their national renewable expansion plans. In conclusion, it can be stated that any long-term planning to incorporate CSP plants into power systems must consider not only the technical and economic aspects of system integration, but also the potential future welfare effects on local economies. 


\section{Acknowledgments}

The authors would like to thank Sascha Samadi and Thomas Fink (Wuppertal Institute), Kornelis Blok (Utrecht University, Netherlands) and Johannes Kretschmann (Fichtner GmbH, Stuttgart) for their helpful comments, suggestions, and ideas.

\section{References}

Aga, V., Boschek, E., Simiano, M. The value of dispatchability for CSP plants under different market scenarios. Proceedings of 17th International SolarPACES Symposium on Solar Thermal Concentrating Technologies. Granada, 2011.

AUPTDE, 2007. Electrical Power Stations in the Arab Countries. Arab Union of Producers, Transporters, and Distributors of Electricity (AUPTDE), Amman. $<$ http://www.auptde.org/>

Bartels, M., 2009. Cost efficient expansion of district heat networks in Germany. Oldenburg Industrieverlag, Munich.

Benkhadra, A., 2010. Le projet Marocain integré d'énergie éolienne. Discours à Tanger, 28 juin 2010. Tangiers.

Brand, B., Missaoui, R., The cost-efficient integration of CSP plants into the electricity system of Tunisia. Proceedings of 17th International SolarPACES Symposium on Solar Thermal Concentrating Technologies. Granada, 2011.

Brand, B., Zingerle, J., 2010. The renewable energy targets of the Maghreb countries: Impact on electricity supply and conventional power markets. Energy Policy, doi:10.1016/j.enpol.2010.10.010

CREG, 2010. Programme indicatif des besoins en moyens de production d'électricité 20102019. Commission de Régulation de l'Electricité et du Gaz (CREG), Algiers.

Dii, 2011. Facts at a glance. Desertec Industrial Initiative, Munich. <http://www.diieumena.com/uploads/media/Dii_Factsheet_11.12_EN.pdf $>$.

EPIA,2010: Market outlook 2010. Brussels, May 2010. <www.epia.org>.

EWEA,2009: The Economics of Wind Energy. European Wind Energy Association, Brussels, 2009. <www.ewea.org>

Fraunhofer and Ernst \& Young, 2011. Middle East and North Africa Region, Assessment of the Local Manufacturing Potential for Concentrated Solar Power (CSP) Projects, Report for the World Bank, January 2011 
Goebel, O., 2010. Shams One 100 MW CSP Plant in Abu Dhabi - Update on Project Status. Proceedings of 16th International SolarPACES Symposium on Solar Thermal Concentrating Technologies. Perpignan.

Giebel, G. (2005). Wind Power has a Capacity Credit - A Catalogue of 50+Supporting Studies. WindEngEJournal, <windeng.net>, 2005.

Giuliano, S., Buck, R., Eguiguren, S. Analysis of solar thermal power plants with thermal energy storage and solar-hybrid operation strategy. Journal of Solar Energy Engineering, Volume 133, Issue 3 (2011). doi:10.1115/1.4004246

GIZ, 2011. Etude Stratégique du Mix Energétique pour la Production d'Electricité en Tunisie, in publication, Tunis 2011.

Hajroun, M., 2010. Le marché d'électricité au Maroc. Vu d'ensemble et aperçu juridique. Moroccan Ministry of Energy, Mining, Water and Environment (MEMEE), Rabat.

Helioclim, 2010. SoDa database. <http://www.soda-is.com/eng/index.html>, Paris.

IEA, 2009: Technology Roadmap Wind Energy 2009. International Energy Agency, Paris, 2009.

IEA, 2010: Technology Roadmap Solar Photovoltaic Energy 2010. International Energy Agency, Paris.

Joskow, P., 2010. Comparing the costs of intermittent and dispatchable electricity generating technologies. Massachusetts Institute of Technology, Center for Energy and Environmental Policy Research. Working Paper. http://econpapers.repec.org/paper/meewpaper/1013.htm / >

Junginger, M. van Sark, W., Faaij, 2010. A. Technology learning in the Energy Sector. Edward Elgar Publishing. ISBN 978-1-84844-8346. Cheltenham.

Kost, C., Schlegel, T., 2010. Studie Stromgestehungskosten erneuerbare Energien. Fraunhofer Institut für Solare Energiesysteme (ISE), December 2010, Freiburg.

Masen, 2010. Moroccan Agency for Solar Energy. Rabat. <www.masen.ma>

MEM, 2011. Programme des Energies Renouvelables et de l'Efficacité Energétique. Ministère de l'Energie et des Mines, <http://www.mem-algeria.org/ francais/index.php?page $=$ enr $>$. Algiers

Montes , M.J., Abánades, A., Martínez-Val, J.M., Valdés, M., 2009. Solar multiple optimization for a solar-only thermal power plant using oil as heat transfer fluid in the parabolic trough collectors. Solar Energy, 83, 1, 2009: 2165-2176.

Nagl. S, Fürsch, M., Jägemann, C., 2011. The economic value of storage in renewable power systems - the case of thermal storage in concentrating solar plants. Working paper $N^{\circ} 8 / 2011$. Institute of Energy Economics at the University of Cologne. 
NREL, 2010. System advisor model, version 2010.11.9. <www.nrel.gov/analysis/sam>. Golden, Colorado.

ONE, 2008. Quand l'énergie vient du vent. Office National d'Electricité. Casablanca.

ONE, 2011. Chiffres clés 2010. <http://www.one.org.ma/>. Casablanca.

Photon, 2011. New PV factories. Photon International magazine, May 2011 issue, p.117.

Poullikkas, A., Hadjipaschalis, I., Kourtis, G., 2010. The cost of integration of parabolic trough CSP plants in isolated Mediterranean power systems. Renewable and Sustainable Energy Reviews 14, 1469-1476. doi:10.1016/j.rser.2010.01.003.

Sargent \& Lundy, 2009. Assessment of Parabolic Trough, Power Tower, and Dish Solar Technology. Cost and Performance Forecasts. Final Draft Prepared for Department of Energy and Sandia National Laboratory. Chicago.

Sioshansi, R., Denholm, P., 2010. The value of concentrating solar power and thermal energy storage. NREL Technical report NREL-TP-6A2-45833. Golden, Colorado.

Swider, D., Weber, C. 2005. The effects of stochastic electricity market modeling on estimating additional costs of intermittent RES-E integration. IAEE European conference 2005, Stuttgart.

UfM, 2011. The UfM Mediterranean Solar Plan is on its way. Press release of the Secretariat of the Union for the Mediterranean, July 7, 2011. <http://www.ufmsecretariat.org/wpcontent/uploads/2011/07/PressRelease_07062011_ENERGY_MSP.pdf >. Barcelona.

Viebahn, P., et al., The potential role of concentrated solar power (CSP) in Africa and Europe - A dynamic assessment of technology development, cost development and life cycle. Energy Policy (2010), doi:10.1016/j.enpol.2010.09.026 